\title{
On the possibility of non-fat frying using molten glucose
}

Article

Accepted Version

Al-Khusaibi, M., Tarmizi, A. H. A. and Niranjan, K. (2015) On the possibility of non-fat frying using molten glucose. Journal of Food Science, 80 (1). E66-E72. ISSN 0022-1147 doi: https://doi.org/10.1111/1750-3841.12713 Available at https://centaur.reading.ac.uk/43508/

It is advisable to refer to the publisher's version if you intend to cite from the work. See Guidance on citing.

To link to this article DOI: http://dx.doi.org/10.1111/1750-3841.12713

Publisher: Wiley

All outputs in CentAUR are protected by Intellectual Property Rights law, including copyright law. Copyright and IPR is retained by the creators or other copyright holders. Terms and conditions for use of this material are defined in the End User Agreement.

\section{www.reading.ac.uk/centaur}

\section{CentAUR}

Central Archive at the University of Reading

Reading's research outputs online 

On the possibility of non-fat frying using molten glucose Mohammed Al-Khusaibi*, Azmil Haizam Ahmad Tarmizi ${ }^{\ddagger}$ and Keshavan Niranjan**

6 *College of Agricultural and Marine Sciences, Sultan Qaboos University, PO Box 34, Al-Khod

7 123, Sultanate of Oman. Email: mohamedk@squ.edu.om

$8 \quad \ddagger$ Malaysian Palm Oil Board, 6 Persiaran Institusi,, Bandar Baru Bangi, 43000 Kajang, Selangor,

9 Malaysia. Email: azmil_haizam@mpob.gov.my

$1{ }^{* *}$ Department of Food and Nutritional Sciences, University of Reading, Whiteknights PO Box

11 226, Reading RG6 6AP (UK)

12

13 Word count:4646

14

15 Short version of title: Glucose Frying

16

$17 * *$ Corresponding author: email: afsniran@ reading.ac.uk 


\section{ABSTRACT}

22 Fried products impose a health concerns due to considerable amount of oil they contain.

23 Production of snack foods with minimal oil content and good management of oil during frying to

24 minimise the production of toxic compounds continue to be challenging aims. This paper aims to

25 investigate the possibility of producing a fat-free food snack by replacing frying oil with a non-

26 fat medium. Glucose was melted and its temperature was then brought to $185^{\circ} \mathrm{C}$ and used to fry

27 potato strips, to obtain a product referred here as glucose fries. The resulting product was

28 compared with French fries prepared conventionally under conditions that resulted in similar

29 final moisture content. The resulting products were also examined for crust formation, texture

30 parameters, colour development and glucose content. Stereo microscope images showed that

31 similar crusts were formed in the glucose fries and French fries. Texture parameters were found

32 to be similar for both products at $5 \mathrm{~mm}$ and $2 \mathrm{~mm}$ penetration depth. The maximum hardness at

$332 \mathrm{~mm}$ penetration depth was also similar for both products, but different from cooked potato. The

34 colour development which characterised French fries was also observed in glucose fries. The

35 glucose content in glucose fries was found to be twice the content of French fries, which is to be

36 expected since glucose absorbed or adhered to the surface. In conclusion, glucose fries, with

37 similar texture and colour characteristics to that of French fries, can be prepared by using a non-

38 fat frying medium.

$40 \quad$ Practical Application: 
41 Frying has always been carried out using a medium that is essentially fat, which inevitably enters

42 the product and has health implications. This paper explores whether we could use non-fat frying 43 medium, like molten glucose, to obtain fat free French fries - known as Glucose fries. 


\section{Introduction}

45 Fried foods are very popular for their unique organolaptic properties such as color, texture and

46 flavor. Recently, the amount of oil absorbed during frying has become one of the most important

47 quality factors. This is because the current nutrition guidelines recommend consumers to lower

48 the intake of dietary fat, especially saturated fat. Fat is believed to play a role in the development

49 of several diseases such as cardiovascular diseases (Diniz and others 2004; Prospective Studies

50 Collabortion, 2007), obesity, and type II diabetes (Hu and others 2001) and may contribute to the

51 risk of sill birth (Frias and others 2011). In addition, some toxic compounds might be produced

52 due the degradation of oil under the high frying temperatures $\left(160-180^{\circ} \mathrm{C}\right)$ and become a

53 potential hazard to consumers (Vahcic and Hruskar 1999; Billek 2000). Despite the awareness of

54 consumers about the negative impacts of fatty foods, the consumption of such snacks is still

55 significant (Dueik and Bouchon 2011).

56 During the last two decades, understanding the mechanism and lowering oil uptake of chips and

57 French fries during frying has received considerable research attention with methods such as

58 blanching (Pedreschi and Moyano 2005), drying (Krokida and others 2001; Song and others

59 2007), vacuum frying (Garayo and Moreira 2002; Yagua and Moreira 2011), and high pressure

60 (Al-Khusaibi and Niranjan 2011), being used in conjunction with frying. However, the oil

61 content in the fried products is still significant, and the production of snack foods with minimal

62 oil content and good management of oil during frying to minimise the production of toxic

63 compounds, continuing to be challenging aims.

64 During frying the formation of crust is essential for the development of product texture (Luyten

65 and others 2004). Moreover, Maillard reactions take place in the crust between sugars and amino 
66 acids, which are responsible for the colour and flavour development (Marquez and AÑOn 1986;

67 Rodriguez-Saona and Wrolstad 1997).

68 Glucose is a monosaccharide that is found in natural products such as fruits, juices and honey, in

69 addition to it being a key component of blood. Glucose can be found into two forms of the D-

70 configuration: alpha-D-(+)-glucose and Beta-D-(-)-glucose. Their melting points are 146 and

$71150{ }^{\circ} \mathrm{C}$, respectively (Tzia and others 2012). When sugars, including glucose, are heated above

72 the melting temperature, either in crystalline form or as syrup, they undergo caramelization

73 which results in the so-called caramel colour and flavour development. The temperature of

74 molten glucose can be brought up to normal frying temperatures $\left(160-190{ }^{\circ} \mathrm{C}\right)$ at which Maillard

75 reactions and colour development can occur. Luna and Aguilera (2014) have recently studied and

76 modelled transient colour development in various types of molten sugars over a range of

77 temperatures between $160^{\circ} \mathrm{C}$ and $200^{\circ} \mathrm{C}$. The aim of this paper is to investigate the possibility of

78 producing a fat-free potato snack, referred to as glucose fries here, using molten glucose as a

79 frying medium. The crust, texture and colour of the new product is compared with conventionally

80 produced French fries prepared in palm olein, under otherwise similar conditions of temperature

81 and frying time required to attain similar values of final moisture contents.

\section{Materials and Methods}

\section{Samples preparation}

85 Potatoes (Solanum tuberosum L.) Maris Piper variety was purchased from local suppliers and 86 were peeled manually, cut into $\times 10 \times 45 \mathrm{~mm}$ strips, and blanched at $85^{\circ} \mathrm{C}$ for 5 minutes in a 7 - $\mathrm{L}$ 87 capacity water bath with a ratio of potato to water of 1:60 (w/v). Some strips were cooked in the 
88 same water bath at $95{ }^{\circ} \mathrm{C}$ for 8 minutes and used to compare the colour and texture with French

89 fries and glucose fries.

90 Glucose fries were prepared by frying the strips in molten glucose (Dextorse anhydrous,

91 Brenntag Limited, UK) at $185^{\circ} \mathrm{C}$ for 2 minutes in a $3 \mathrm{~L}$ capacity domestic fryer controlled by a

92 temperature process controller (CAL9500P, CAL control Ltd, UK). The frying time of 2 mins

93 was chosen by undertaking preliminary experiments which showed the development of golden-

94 yellow colour and an acceptable final moisture content of 64\% (expressed on a dry weight basis).

95 To compare the resulting product, conventional French fries having the same final moisture

96 content were prepared by frying the blanched strips in Palm Olein (Britannia Food Ingredients,

97 UK), at the same temperature $\left(185^{\circ} \mathrm{C}\right)$ for 3.5 minutes.

\section{Moisture content}

99 The moisture content of blanched French fries and glucose fries was determined by drying the

100 samples in a vacuum oven at $50^{\circ} \mathrm{C}$ and 0.5 bar, for at least 24 hours until a constant weight was

101 achieved.

\section{Microscopic analysis}

103 Cross-sections of the samples were prepared by cutting the samples with a sharp blade prior to

104 microscopic analysis. The sections were viewed under a Stereo Microscope with integrated LED

105 illumination and a digital camera (Leica EZ4-D, Leica Microssystems, Wetzlar, Germany). The 106 images were acquired and transferred to a computer with LAS EZ software, v1.30.

\section{Texture measurement}


108 The texture of the products was analysed by Brookfield texture analyser fitted with $25 \mathrm{~kg}$ loading

109 cell (CT3, Brookfield Engineering Laboratories, USA). A single cycle puncture test was carried

110 out using a $2 \mathrm{~mm}$ probe with a test speed of $1 \mathrm{~mm} / \mathrm{s}$ at room temperature. The penetration depth

111 was either $5 \mathrm{~mm}$ to study the texture of the core or $2 \mathrm{~mm}$ which accounted mainly for the crust

112 region. The data were collected and analysed by software provided by the analyser manufacturer

113 (TexturePro CT v1.2 software). The test was carried out on 6 samples (from two batches, taking

1143 replicates from each batch), each sample punctured at 2 random positions. An average value is

115 reported with deviations.

\section{Colour measurement}

117 The colour of fresh potato and cooked samples was measured using HunterLab colorimeter 118 (Color-Quest $^{\circledR}$, Hunter Association Laboratory, USA). CIE Lab L* (lightness), a* (redness) and $119 \mathrm{~b}^{*}$ (yellowness) colour space values were obtained at 8 different positions on 3 samples aligned 120 to each other taken from two separate batches.

\section{Oil and Glucose content determination in the product}

123 The oil content was determined by the Soxhlet extrcation, according to the AOCS method (Am 124 5-04) after drying and grinding the samples. Extraction of glucose was carried out according to 125 Rodríguez-Galdón and others (2010) with some modifications. 5 grams of ground samples were 126 weighed in centrifuge tubes and mixed with $10 \mathrm{ml}$ of $30 \%$ ethanol. The tubes were then placed in 127 an ultrasound bath for 10 minutes and then centrifuged at $10000 \mathrm{rpm}$ for 10 minutes. The 128 supernatant was carefully recovered in a test tube with screw cover. Another $5 \mathrm{ml}$ of the ethanol 129 solution was added to the tubes containing the pellet and the tubes were again placed in 
130 ultrasound bath and centrifuged as above. The supernatant was recovered in the same test tube.

131 The solution was filtered by passing through a $0.45 \mu \mathrm{m}$ filter GHP (Waters Corporation, 132 Millford, MA, USA).

133 Glucose content was determined by means of High Performance Anion Exchange 134 Chromatography with Pulsed Amperometric Detection (HPAEC-PAD) (Osman and others 135 2010). A Dionex system (Dionex corporation, Surrey, UK) consisting of a GS50 gradient pump, 136 an ED50 electrochemical detector with a gold working electrode, a LC25 chromatography oven, 137 and an AS50 autosampler was used (Dionex corporation, Surrey, UK). The column used was a 138 pellicular anion-exchange resin based column, CarboPac PA-1 analytical $(4 \times 250 \mathrm{~mm})$. It was 139 maintained at $25{ }^{\circ} \mathrm{C}$ and elution was performed using gradient concentrations of sodium 140 hydroxide and sodium acetate solutions at a flow rate of $1 \mathrm{ml} / \mathrm{min}$.

\section{Statistical analysis}

142 Two batches of each treatment and control samples were produced under the same conditions. 143 Each batch was analysed for moisture, colour, and texture as described above. The mean values 144 of all the samples drawn from the two batches (each batch with 3 replicates) are reported \pm 145 standard deviation. The differences between means were assessed by one-way analysis of 146 variance (ANOVA) using SPSS statistics (v17.0 for Windows).

\section{Results and Discussion}

149 The frying process is characterised by mass transfer between food and frying medium, with the

150 medium being absorbed by product and moisture being transferred to the medium. Fried products 
151 are characterised by a significantly reduced moisture content compared to the raw materials. The

152 moisture content of the raw sample was $82.65 \pm 1.93$ and it was reduced to $64.21 \pm 1.82$ in French

153 fries and $65.35 \pm 3.67$ in glucose fries. Statistical analysis showed that there is no significant

154 difference between the moisture contents of the final products.

155 The development of crust is very essential in French fries and it accounts for the crispy texture.

156 Figure 1 shows cross-section microscope images of glucose fries (1a) and French fries (1b). A

157 crust region can be noticed in both sets of products. Frying temperature and evaporation of water

158 play key roles in formation of a crust region in fried products. During frying, water vapour is

159 formed and transferred through the surface of the product due to pressure and concentration

160 gradients. This results in the development of pores and crust formation (Sahin and Sumnu 2009).

161 In both frying processes, conventional frying and glucose frying, the difference between the

162 saturation temperature of water $\left(100^{\circ} \mathrm{C}\right)$ and the frying medium was high enough to result in a

163 high vaporization rate. It has been reported that the crust is well defined under high frying

164 temperatures $\left(>150^{\circ} \mathrm{C}\right)$ and it was less distinguished at low frying temperatures (e.g., $120{ }^{\circ} \mathrm{C}$ )

165 (Nawel and others 2009).

\section{Change in texture of samples}

168 During frying, changes in texture of products occur due to physical, chemical and microstructural 169 changes. Texture is an important parameter to study the sensory quality of fried products. In 170 order to examine texture development in prepared samples, A penetration test was carried out 171 with a 2-mm diameter probe. As mentioned earlier, the depth of penetration was either $5 \mathrm{~mm}$ to 172 study the internal texture of the samples or $2 \mathrm{~mm}$ which was intended to study the crust texture 
173 properties. Figure 2 shows examples of force-distance curves of different samples at different

174 penetration depths. When the probe penetrates to $5 \mathrm{~mm}$ (figure 2, a-c) in the samples, a maximum

175 stress is reached after which the sample breaks, and this is true for all samples. With regard to the

$1762 \mathrm{~mm}$ penetration graphs (2 d-f), this is only true in the case of the cooked sample since the

177 surface breaks and the probe continues travelling through the depth. In the case of the French

178 fries and glucose fries, instead, a maximum force is reached at the target penetration depth (2

$179 \mathrm{~mm}$ ) followed by recovery without the sample disintegration. This suggests that the product has

180 some elasticity at $2 \mathrm{~mm}$ depth which is due to the crust. Lima and Singh (2001) studied the

181 mechanical properties of the crust of fried potato cylinders and reported that the crust showed

182 viscoelastic behaviour. It has also been shown by Ross and Scanlon (2004) that the elastic

183 modulus of potato crust increases with frying time, due to the changes occurring in crust

184 thickness. Examples of the force-distance curves are also shown in figure 3.

185 The texture analysis parameters are shown in table 1; these are hardness, deformation at hardness

186 and hardness work which is the energy at the maximum hardness. In general, the values of the

187 three parameters decrease as the samples get cooked; this is the case for, both, $5 \mathrm{~mm}$ and $2 \mathrm{~mm}$

188 penetration tests. The values of these parameters for French fries and glucose fries are not

189 significantly different $(\mathrm{p}>0.05)$. In the case of the $2 \mathrm{~mm}$ penetration test, the maximum hardness

190 is recorded at $1.0 \mathrm{~mm}$ for cooked samples, while it was 1.6 and $1.78 \mathrm{~mm}$ in the case of French

191 fries and glucose fries. The difference between cooked samples and fried samples (glucose and

192 French fries) may be attributed to the mechanical properties of the crust which strongly

193 influences the strain at the maximum stress. In order to eliminate the possibility of glucose glass

194 transition influencing measurements, all texture measurements were carried out at room

195 temperature. At this temperature, any glucose adhering to the sample surface could be removed 
196 because the glucose tended to solidify rapidly on cooling to $20^{\circ} \mathrm{C}$. Thus, the vitreous glucose was

197 removed so it does not contribute to the force required to penetrate the sample. Moreover, the

198 texture force-time analysis at $2 \mathrm{~mm}$ penetration depth is used to distinguish the effect of the crust,

199 as mentioned earlier.

200 Change in colour of samples

201 The colour is one of the essential parameters determining the acceptability of fried products. In

202 colour measurement, $\mathrm{L}^{*} \mathrm{a} \mathrm{b}^{*}$ colour space is most common and suitable for direct comparison

203 with sensory data (Hunt and Pointer 2011). Luminosity colour component $\left(L^{*}\right)$, which ranges

204 from 0 to 100 , tends to decrease with the frying temperature and time since potato strips get

205 darker (Pravisani and Calvelo 1986; Nourian and Ramaswamy 2003) due to Maillard reactions.

206 In table 2 , the $\mathrm{L}^{*}$ value for the blanched and cooked samples was not significantly different, this

207 is also true in the case of parameters $a^{*}$ and $b^{*}$. The lightness value $\left(\mathrm{L}^{*}\right)$ decreased in French and

208 glucose fries with marginally lower values being observed in the case of glucose fries. This might

209 be due to the fact that glucose gets caramelized at high temperature influencing the product

210 colour. The colour parameters for glucose and French fries are significantly different from the

211 blanched and cooked samples. The values of $a^{*}$ and $b^{*}$ observed in this work are similar to those

212 reported for fried French fries by (Segnini and others 1999). There was no significant difference

213 found between the French fries and glucose fries in terms of a* values, while the difference was

214 significant in the case of $b^{*}$, which shows more darkening to occur in the case of French fries.

215 It is noteworthy that the colour developed by any product during frying depends on the product as

216 well as the frying medium, the frying time and water removed in the process. The key question is

217 whether the kinetics of colure change in glucose will affect the data reported in this study. Using 
218 glucose for frying involves melting the glucose in an oven at $150^{\circ} \mathrm{C}$. The melting process is a

219 slow and very critical process. Fresh molten glucose is initially colourless. Exposure to high

220 temperatures, above the melting point, causes caramelization, and thermal degradation of

221 saccharides accompanied by brown colour development and production of a caramel flavour

222 (Belitz and others 2009). Recently, Luna \& Aguilera (2014) studied changes occurring in molten

223 sugars crystals (Crystalline glucose, fructose and sucrose) at temperatures in the range $160-200$

$224{ }^{\circ} \mathrm{C}$. The study reported that, amongst the sugars studied, Glucose showed the lowest change in

225 lightness. Further, perceptible changes in colour began after 15 mins at $190 \mathrm{C}$ and changes in

226 colour over 5 minute intervals thereafter was relatively small up to 20 mins. In this study the

227 frying times as well as the duration of glucose usage were significantly lower, so the influence of

228 glucose colour change on product colour is expected to be negligible.

229 Nevertheless, it is true that chemical changes will occur if the glucose is used for extended

230 periods of time. After prolonged usage, the glucose tends to appear darker and thicker. In

231 addition to caramelizaion, maillard reactions also occur due to the reactions between the carbonyl

232 group $(>\mathrm{C}=\mathrm{O})$ of glucose and amino group of a protein or amino acid in any product (Newton

233 2007). Thus a major disadvantage of this process is the limitation placed by these reactions on the

234 duration of use of glucose. This is an area which needs further investigation, together with

235 sensory evaluation which will eventually determine consumer acceptability of any product

236 employing this novel frying method. 
239 Frying in a glucose medium causes transfer of glucose into the product, in addition to glucose

240 that might adhere to the surface. The glucose contents of fresh potato, French fries and glucose

241 fries are presented in figure 4. The amount of glucose in glucose fries increases from $5.3 \mathrm{~g} / 100 \mathrm{~g}$

242 dry matter in fresh samples to $10.4 \mathrm{~g} / 100 \mathrm{~g}$ dry matter. This roughly doubling of glucose content

243 undoubtedly increases product carbohydrates content, which remains a health concern for some.

244 However, the fat has been virtually eliminated and this is a major advantage. An attempt can be

245 made to estimate the total Calories (kcal) associated with glucose and fat in fresh potato, French

246 fries and Glucose fries, assuming that there is no fat in fresh potato and glucose fries and all other

247 components remain the same. Table 3 shows the results of such an estimation made on the basis

248 that glucose will yield $4 \mathrm{kcal} / \mathrm{g}$ and oil will yield $9 \mathrm{kcal} / \mathrm{g}$. It can be clearly seen that the calories

249 associated with French fries will be significantly higher than glucose fries per 100g potato dry

250 matter. In general, the amount of glucose in potato tubers is very critical for chips and French

251 fries production. The initial amount of glucose differs between varieties and even among

252 cultivars of the same variety, this is due to differences in starch to glucose conversion process

253 during postharvest storage (Bradshaw and Ramsay 2009). The use of potato with low reducing

254 sugars (glucose and fructose) is essential in the production of chips and French fries to avoid

255 excessive darkening (Gould 2001). Reconditioning potato tubers at temperatures higher than

256 storage temperatures is a common strategy employed to reduce the level of reducing sugars, and

257 seems to be appropriate for glucose frying to reduce the final total amount of glucose.

259 Conclusion

260 In this paper, molten glucose was used as a frying medium instead of oil to prepare fried potato 261 product known here as glucose fries. Frying in glucose produced a product of similar properties 
262 to French fries. Stereomicroscope images showed that a crust was formed in both the types of 263 fries. Texture and colour analysis revealed that glucose fries developed a similar texture and 264 colour to that of French fries, although the latter was marginally lighter when the two products

265 were fried to the same final moisture content. The glucose content in glucose fries was roughly 266 twice that of French fries, but the oil content is virtually eliminated, resulting in significantly 267 lower calorie content. This work demonstrates that a fat-free snack food can be produced by 268 using non-fat frying medium with melting point close to normal deep fat frying temperatures.

269 Further research is still needed to understand mechanisms and human sensory effects. 
271 Author Contributions:

272 K. Niranjan: Designed the study and interpreted the results

273 M. Al-Khusaibi: Did the experimental work, analysis and helped draft the paper

274 Azmil Haizam Ahmad Tarmizi: Did the experimental work, analysis and helped to draft the 275 paper

276

277 


\section{References}

279

Al-Khusaibi MK, and Niranjan K. 2011. "The Impact of Blanching and High-Pressure Pretreatments on Oil Uptake of Fried Potato Slices." Food and Bioprocess Technology: 1 -9 .

Belitz HD, Grosch W, Schieberle P. 2009. Carbohydrates. Food Chemistry. Berlin, Springer.

Billek G. 2000. Health aspects of thermoxidized oils and fats. European Journal of Lipid Science and Technology 102(8-9): $587-593$.

Bradshaw JE, Ramsay G. 2009. Potato Origin and Production. Advances in Potato Chemistry and Technology. J. Singh and L. Kaur. New York, Elsevier Inc.

Diniz YS, Cicogna AC, Padovani CR, Santana LS, Faine LA, Novelli EL. (2004). Diets rich in saturated and polyunsaturated fatty acids: metabolic shifting and cardiac health. Nutrition 20(2): $230-234$.

Dueik V, Bouchon P. 2011. Development of Healthy Low-Fat Snacks: Understanding the Mechanisms of Quality Changes During Atmospheric and Vacuum Frying. Food Reviews International 27(4): 408 - 432.

Frias AE, Morgan TK, Evans AE, Rasanen J, Oh KY, Thornburg KL, Grove KL. 2011. Maternal High-Fat Diet Disturbs Uteroplacental Hemodynamics and Increases the Frequency of Stillbirth in a Nonhuman Primate Model of Excess Nutrition. Endocrinology 152(6): 2456 -2464 .

Garayo J, Moreira R. 2002. Vacuum frying of potato chips. Journal of Food Engineering 55(2): $181-191$.

Gould WA. 2001. Potatoes and Potato Chips. Snack Foods Processing. E. W. Lusas and L. W. Rooney. London, CRC Press.

Hu FB, van Dam RM, Liu S. 2001. Diet and risk of Type II diabetes: the role of types of fat and carbohydrate. Diabetologia 44(7): 805 - 817.

Hunt RWG, Pointer MR. 2011. Colour Vision. Measuring Colour, John Wiley \& Sons, Ltd: pp 1 $-17$.

Krokida MK, Oreopoulou V, Maroulis ZB, Marinos-Kouris D. 2001. Effect of pre-drying on quality of french fries. Journal of Food Engineering 49: 347 - 354. 
Lima I, Singh RP. 2001. Viscoelastic behavior of fried potato crust. Journal of Texture Studies 32(2): $131-141$. and Sucrose at High Temperatures. Food Biophysics 9: $61-68$.

311 Luyten H, Plijter JJ, Vliet TV. 2004. Crispy/Crunchy Crusts Of Cellular Solid Foods: A Literature Review With Discussion. Journal of Texture Studies 35: 445 - 492.

Marquez G, Anon MC. 1986. Influence of Reducing Sugars and Amino Acids in the Color Development of Fried Potatoes. Journal of Food Science 51(1): 157 - 160.

Nawel A, Olivier V, Trystram G. 2009. Heat and Mass Transfer During Frying. Advances in Deep-Fat Frying of Foods. S. G. Sumnu and S. Sahin. New York, CRC Press: 5 - 32.

Newton DE. 2007. Food Chemistry. New York, Facts On File, Inc.

Nourian F, Ramaswamy HS. 2003. kinetics of quality change during cooking and frying of potatoes: Part II: Color. 26: 395 - 411.

Osman A, Tzortzis G, Rastall RA, Charalampopoulos D. 2010. A comprehensive investigation of the synthesis of prebiotic galactooligosaccharides by whole cells of Bifidobacterium bifidum NCIMB 41171. Journal of Biotechnology 150(1): 140 - 148.

Pedreschi F, Moyano P. 2005. Oil uptake and texture development in fried potato slices. Journal of Food Engineering 70(4): 557 - 563.

Pravisani CI, Calvelo A. 1986. Minimum Cooking Time for Potato Strip Frying. Journal of Food Science 51(3): $614-617$.

Prospective Studies Collaboration, Lewington S, Whitlock G, Clarke R, Sherliker P, Emberson J, Halsey J, Qizilbash N, Peto R, Collins R. 2007. Blood cholesterol and vascular mortality by age, sex, and blood pressure: a meta-analysis of individual data from 61 prospective studies with 55000 vascular deaths. Lancet 370(9602): 1829 - 1839.

Rodriguez-Saona LE, Wrolstad RE. 1997. Modeling the Contribution of Sugars, Ascorbic Acid, Chlorogenic Acid and Amino Acids to Non-enzymatic Browning of Potato Chips. Journal of Food Science, 62(5): 1001 - 1010

Rodríguez Galdón B1, Ríos Mesa D, Rodríguez Rodríguez EM, Díaz Romero C. 2010. Influence of the cultivar on the organic acid and sugar composition of potatoes. Journal of the Science of Food and Agriculture 90(13): 2301 - 2309. 
337 Ross KA, Scanlon MG. 2004. A fracture mechanics analysis of the texture of fried potato crust. 338 Journal of Food Engineering 62(4): 417 - 423.

339 Sahin S, Sumnu SG. 2009. Introduction. Advances in Deep fat frying of foods. S. Sahin and S. G. 340 Sumnu. London, CRC press: p1.

341 Segnini S, Dejmek P,Oste R. 1999. Relationship between instrumental and sensory analysis of 342 texture and color of potato chips. Journal of Texture Studies 30(6): 677 - 690.

343 Song, XJ, Zhang M, Mujumdar, AS. 2007. Optimization of vacuum microwave predrying and 344 vacuum frying conditions to produce fried potato chips. Drying Technology 25(12): 2027 $345-2034$.

346 Tzia C, Giannou V, Lebesi D, Chranioti C. 2012. Chemistry and Functional Properties of 347 Carbohydrates and Sugars (Monosaccharides, Disaccharides, and Polysaccharides). In: 348 Theodoros Varzakas, Athanasios Labropoulos, Stylianos Anestis. Sweeteners: Nutritional 349 Aspects, Applications, and Production Technology. New York: CRC Press.pp 1-43.

350 Vahcic N, Hruskar M. 1999. Quality and sensory evaluation of used frying oil from restaurants. $351 \quad$ Food Technology and Biotechnology 37(2): $107-112$.

352 Yagua CV, Moreira RG. 2011. Physical and thermal properties of potato chips during vacuum 353 frying. Journal of Food Engineering 104(2): 272 - 283. 
354 Table 1: Texture evaluation of French fries fried at $185^{\circ} \mathrm{C}$ for 2 minutes, glucose fries fried at $190^{\circ} \mathrm{C}$ for 2 355 min and strips blanched at $95^{\circ} \mathrm{C}$ either for 5 or 8 minutes.

\begin{tabular}{|c|c|c|c|c|c|c|}
\hline \multirow[b]{2}{*}{ Sample } & \multicolumn{3}{|c|}{ At $5 \mathrm{~mm}$ penetration depth } & \multicolumn{3}{|c|}{ At $2 \mathrm{~mm}$ penetration depth } \\
\hline & $\begin{array}{l}\text { Hardness } \\
(\mathrm{N})\end{array}$ & $\begin{array}{l}\text { Deformation } \\
\text { at hardness } \\
(\mathrm{mm})\end{array}$ & $\begin{array}{c}\text { Hardness } \\
\text { work } \\
(\mathrm{mJ})\end{array}$ & $\begin{array}{l}\text { Hardness } \\
\text { (N) }\end{array}$ & $\begin{array}{l}\text { Deformation } \\
\text { at hardness } \\
(\mathrm{mm})\end{array}$ & $\begin{array}{c}\text { Hardness } \\
\text { work } \\
(\mathrm{mJ})\end{array}$ \\
\hline Fresh potato & $\begin{array}{c}7.52 \pm 0.60 \\
\mathrm{a}\end{array}$ & $3.88 \pm 1.32 \mathrm{a}$ & $\begin{array}{c}25.95 \pm 2.66 \\
\mathrm{a}\end{array}$ & $\begin{array}{r}7.92 \pm 1.02 \\
\mathrm{a}\end{array}$ & $1.28 \pm 0.09 \mathrm{a}$ & $\begin{array}{r}10.20 \pm 1.06 \\
\mathrm{a}\end{array}$ \\
\hline $\begin{array}{l}\text { Blanched } \\
85^{\circ} \mathrm{C}, 5 \mathrm{~min}\end{array}$ & $\begin{array}{c}4.13 \pm 0.67 \\
b\end{array}$ & $1.32 \pm 0.26 b$ & $\begin{array}{c}13.27 \pm 1.88 \\
b\end{array}$ & $\begin{array}{r}5.50 \pm 0.67 \\
b\end{array}$ & $1.30 \pm 0.14 \mathrm{ab}$ & $5.82 \pm 0.55 b$ \\
\hline $\begin{array}{l}\text { Cooked } \\
\text { samples }\left(95^{\circ} \mathrm{C} \text {, }\right. \\
8 \text { min })\end{array}$ & $\begin{array}{c}2.06 \pm 0.21 \\
\mathrm{c}\end{array}$ & $1.05 \pm 0.19 \mathrm{~b}$ & $4.47 \pm 0.53 c$ & $\begin{array}{r}2.36 \pm 0.22 \\
\mathrm{c}\end{array}$ & $1.00 \pm 0.06 \mathrm{c}$ & $2.29 \pm 0.14 \mathrm{c}$ \\
\hline Glucose fries & $\begin{array}{c}1.28 \pm 0.18 \\
\mathrm{~d}\end{array}$ & $1.80 \pm 0.20 \mathrm{c}$ & $3.45 \pm 0.51 \mathrm{c}$ & $\begin{array}{r}1.28 \pm 0.16 \\
\mathrm{~d}\end{array}$ & $1.78 \pm 0.20 \mathrm{~d}$ & $1.55 \pm 0.24 \mathrm{~d}$ \\
\hline French fries & $\begin{array}{c}1.38 \pm 0.27 \\
\mathrm{~d}\end{array}$ & $1.47 \pm 0.15 \mathrm{bc}$ & $3.15 \pm 0.49 \mathrm{c}$ & $\begin{array}{r}1.48 \pm 0.19 \\
\mathrm{~d}\end{array}$ & $1.55 \pm 0.18 \mathrm{~d}$ & $1.63 \pm 0.21 \mathrm{~d}$ \\
\hline
\end{tabular}

Values represent means \pm standard deviation

Means followed by different letters are significantly different at $95 \%$ confidence level 356

357 
358 Table 2: Colour parameters of potato and fries

\begin{tabular}{lccc}
\hline \multirow{2}{*}{ Samples } & \multicolumn{3}{c}{ Colour parameters } \\
\cline { 2 - 4 } & $\mathrm{L}^{*}$ & $\mathrm{a}^{*}$ & $\mathrm{~b}^{*}$ \\
\hline Fresh potato & $62.49 \pm 1.81 \mathrm{a}$ & $0.69 \pm 0.15 \mathrm{a}$ & $13.36 \pm 0.83 \mathrm{a}$ \\
Blanched $\left(85^{\circ} \mathrm{C}\right.$, & $58.33 \pm 1.24 \mathrm{~b}$ & $-2.63 \pm 0.28 \mathrm{~b}$ & $4.32 \pm 0.85 \mathrm{~b}$ \\
5 min) & & & \\
Cooked $\left(95^{\circ} \mathrm{C}, 8 \mathrm{~min}\right)$ & $59.25 \pm 1.06 \mathrm{~b}$ & $-2.87 \pm 0.20 \mathrm{~b}$ & $4.78 \pm 0.79 \mathrm{~b}$ \\
& & & $19.36 \pm 1.68 \mathrm{c}$ \\
French fries & $54.79 \pm 2.70 \mathrm{c}$ & $-7.39 \pm 0.52 \mathrm{c}$ & $16.94 \pm 1.02 \mathrm{~d}$ \\
& & & \\
\hline
\end{tabular}


362 Table 3: The estimated Calories associated with glucose and oil: a comparison between fresh 363 potato, French fries and glucose fries, taking the calorie contents of glucose and oil to be 4 and 9 $364 \mathrm{kcal} / \mathrm{g}$, respectively

365

\begin{tabular}{cccc}
\hline Product & Glucose content & Oil content & Total kcal (or Cal) \\
& $(\mathrm{g} / 100 \mathrm{~g}$ potato & $(\mathrm{g} / 100 \mathrm{~g}$ & associated with oil \\
& dry matter $)$ & potato dry & and glucose $/ 100 \mathrm{~g}$ \\
& & matter $)$ & potato dry matter \\
Fresh potato & $5.29 \pm 0.39$ & negligible & 21.2 \\
French fries & $4.18 \pm 0.29$ & $23.21 \pm 0.87$ & 225.6 \\
Glucose fries & $10.42 \pm 0.21$ & negligible & 41.7 \\
\hline
\end{tabular}

366

367 


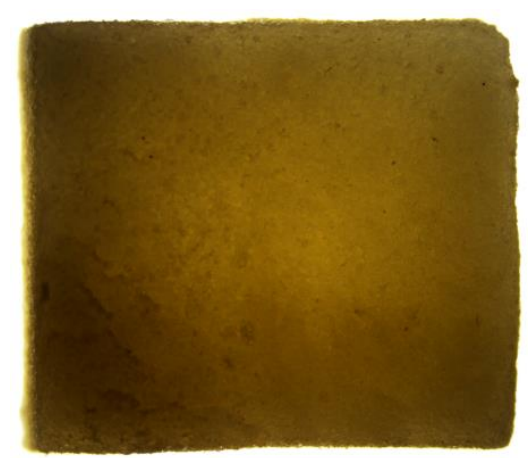

a. Raw potato strip

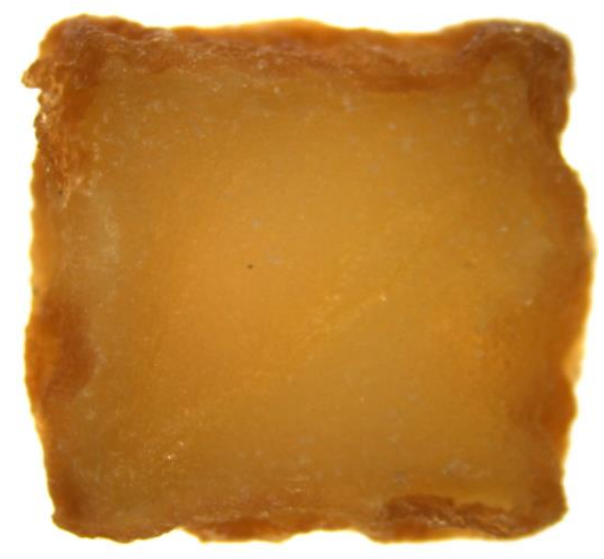

c. Glucose-fries

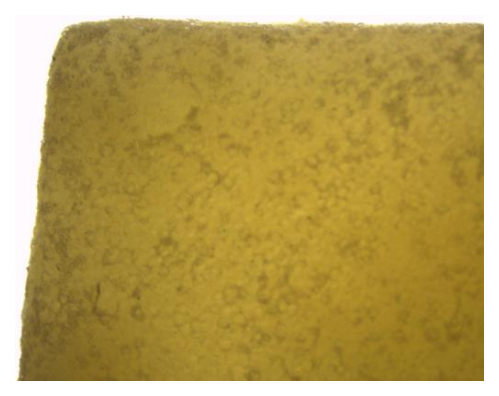

b. Cooked potato strip

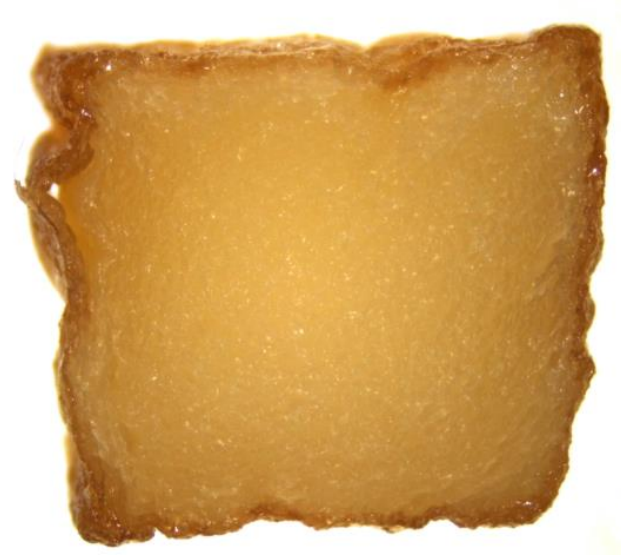

d. French fries

Figure 1: Images from Stereomicoscope (at $8 \mathrm{X}$ magnification) for a cross-section of raw (a), cooked (b), fried in glucose (c) and fried in palm olein (d) potato strips. 

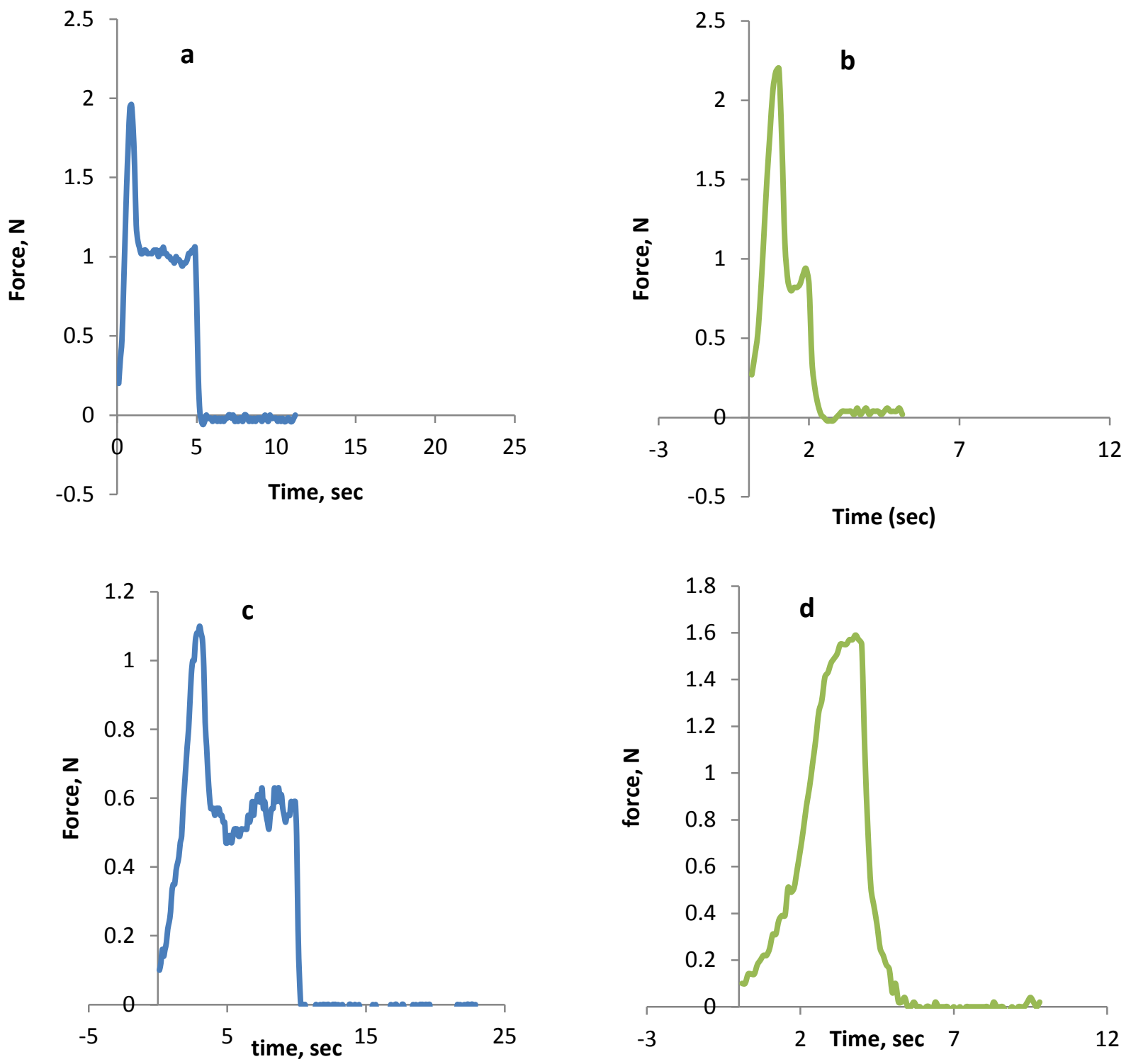

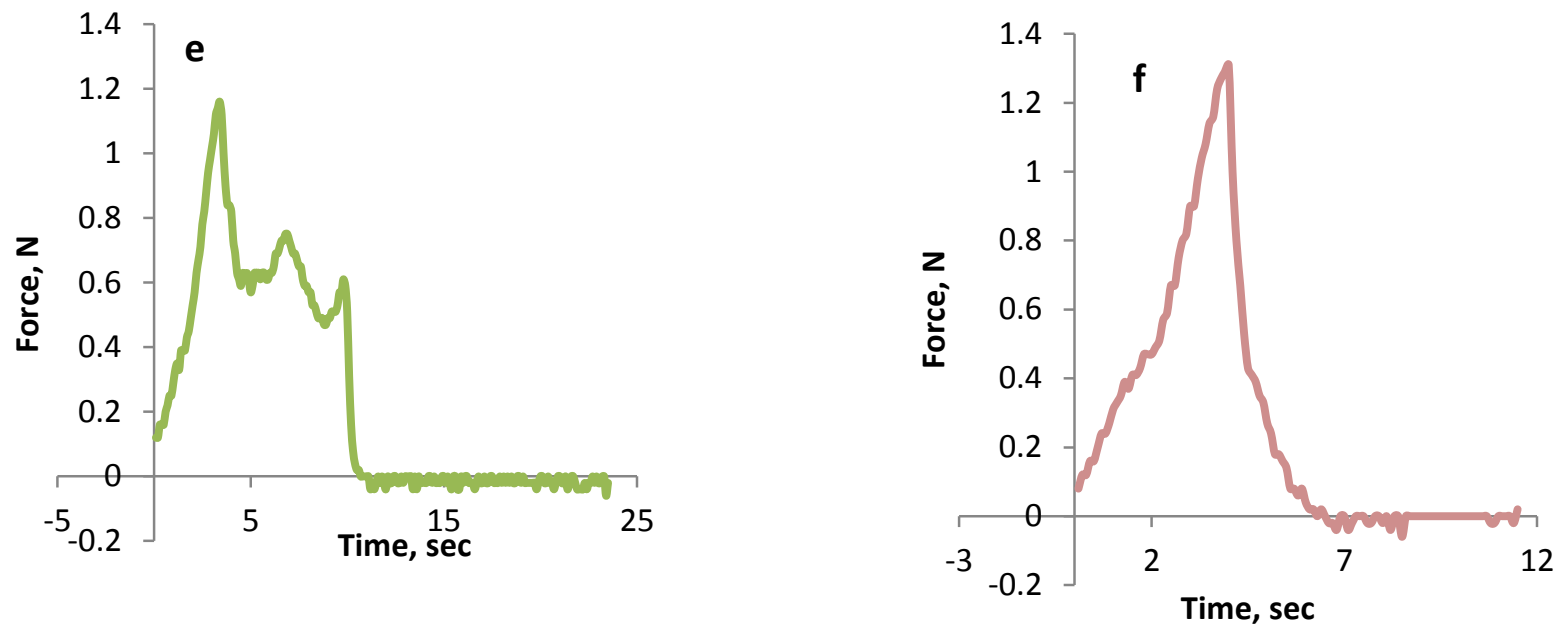

Figure 2: Examples of Force-time curves of blanched sample, French fries and glucose fries at $5 \mathrm{~mm}$ penetration depth (a,c, e) and $2 \mathrm{~mm}$ penetration depth $(\mathrm{b}, \mathrm{d}, \mathrm{f})$ 

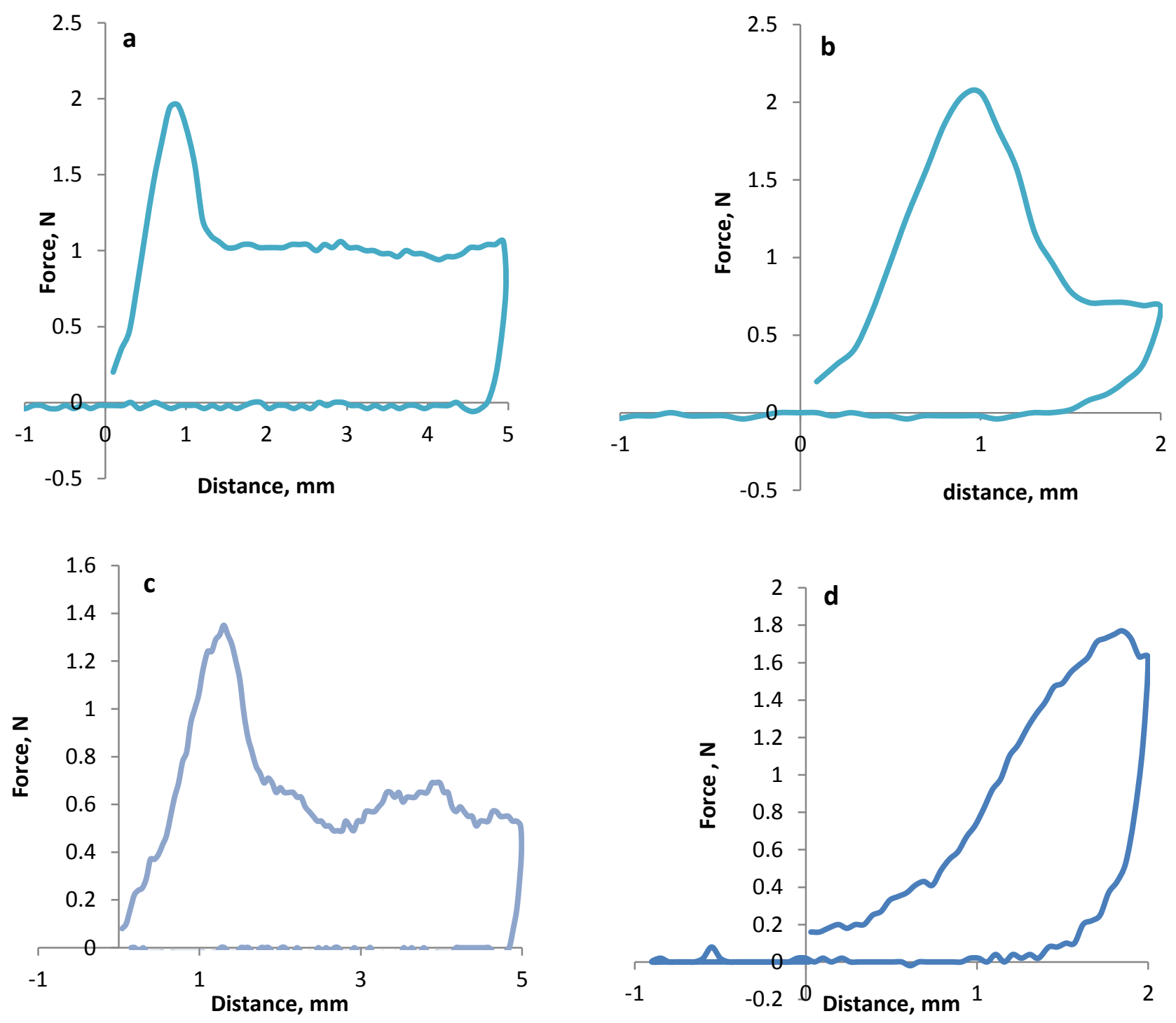

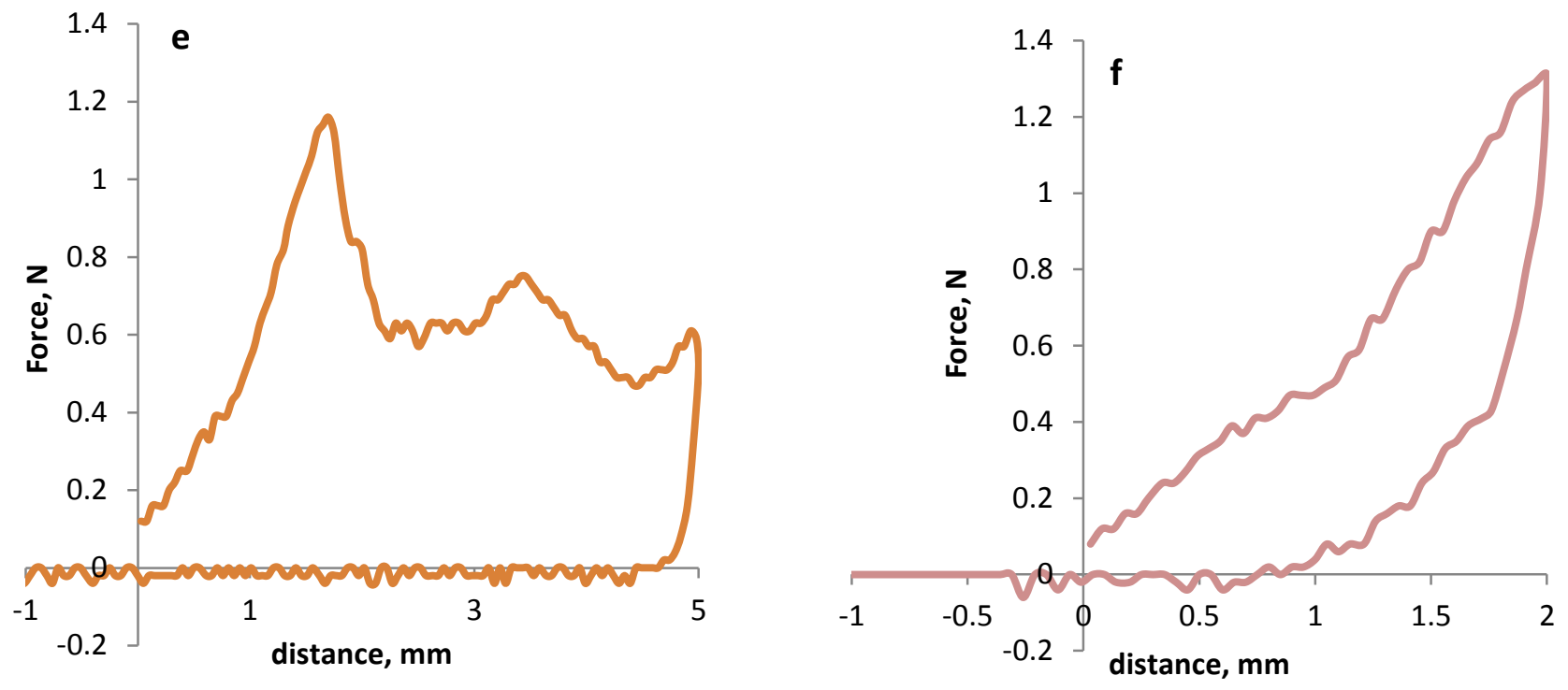

Figure 3: Examples of Force-distance curves of blanched sample, French fries and glucose fries at 5 $\mathrm{mm}$ penetration depth (a ,c, e) and $2 \mathrm{~mm}$ penetration depth $(\mathrm{b}, \mathrm{d}, \mathrm{f})$ 


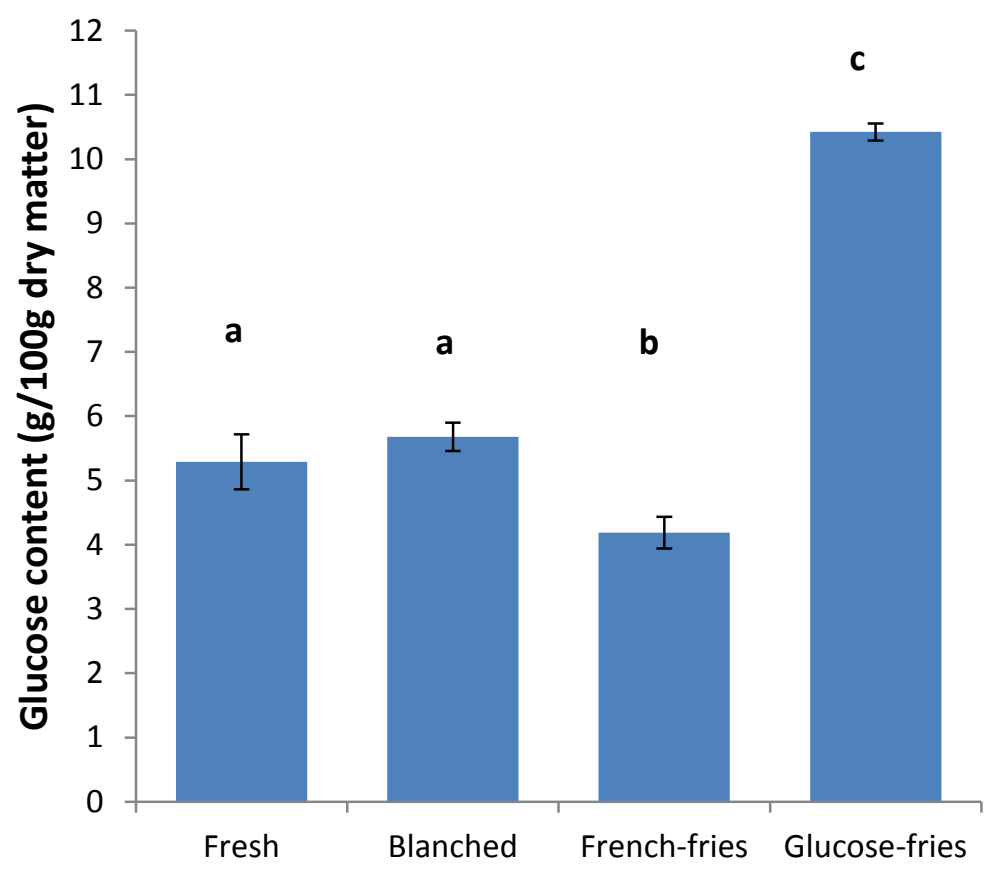

382

Figure 4: Glucose content in fresh, blanched and fried 383 samples, g/100g dry matter. (Different letters indicate significant difference, $\mathrm{p}>0.5$ 